\title{
A Validated Stability-indicating RP-HPLC Method for Piperine Estimation in Black Pepper, Marketed Formulation and Nanoparticles
}

\author{
Bhaskar Kurangi ${ }^{1,2}$, Sunil Jalalpure ${ }^{1,2 *}$ \\ ${ }^{1}$ Dr. Prabhakar Kore Basic Science Research Center, KLE Academy of Higher Education and Research, Nehru Nagar, Belagavi, \\ Karnataka, INDIA. \\ ${ }^{2}$ KLE College of Pharmacy Belagavi, KLE Academy of Higher Education and Research, Nehru Nagar, Belagavi, Karnataka, INDIA.
}

\begin{abstract}
Aim: The aim of the study was to develop and validate a simple stability indicating reversephase High Performance Liquid Chromatography (RP-HPLC) method for quantitative analysis of piperine in Ayurvedic marketed formulation, black pepper and cubosome nanoformulation. Methods: The method was established by using Luna $\mathrm{C}_{18}$ HPLC column using a mobile phase consisting of acetonitrile: $0.01 \%$ ortho phosphoric acid $(60: 40, \mathrm{v} / \mathrm{v}$; $\mathrm{pH} 3$ ), delivered isocratically with flow rate of $1 \mathrm{~mL} / \mathrm{min}$ and detected at $340 \mathrm{~nm}$. The validation of chromatographic parameters and stress testing were performed in accordance with International Conference on Harmonization ( $\mathrm{ICH}$ ) guidelines. Results: The developed method was observed to be specific, linear $\left(r^{2}>0.999\right)$ over the selected range of concentration 0.5 to $20 \mu \mathrm{g} / \mathrm{mL}$, precise (percentage relative standard deviation $<2 \%$ ), with the detection and quantification limit as 0.015 and $0.044 \mu \mathrm{g} / \mathrm{mL}$ respectively. The relevancy of the developed method was analyzed on the piperine entrapped cubosome nanoformulation, which was formulated by fragmentation technique. The entrapment efficiency of piperine for prepared cubosome was observed to be $87.01 \%$. The method was implemented for the estimation of piperine in black pepper. The concentration of piperine in marketed formulation was found to be similar with the labeled concentration. The analyte peak was found to be complete resolved without any interference of additives and degrading products. Conclusion: The validated method was observed to be specific, sensitive and sufficient for the routine analysis of food products, marketed formulations and nanoparticles containing piperine.
\end{abstract}

Key words: RP-HPLC, Piperine, Cubosome, Stress degradation, Ayurvedic marketed formulations.

\section{INTRODUCTION}

Black pepper is widely used as spice and well known for its pungent taste and aroma. It is categorized as Generally Recognized as Safe (GRAS) by the US Food and Drug Administration (FDA) which contains piperine as an active alkaloid constituent. Piperine found in Piper nigrum and Piper longum, belonging to Piperaceae family, which can be used as potential therapeutic agent for targeting various diseases. Piperine exerts wide range of pharmacological activities like antioxidant, anti-arthritic, anti-inflammatory and anti-depressant. Piperine has also been reported for anticancer activity which can be exerted through its immunomodulation characteristics. ${ }^{1}$ Many research for piperine have been performed in combination with other phytochemicals, which have led to increased their bioavailability, prophylactic and therapeutic responses. ${ }^{2,3}$

Since, human recognizing the use of herbal medicines and homemade remedies, these are widely practiced for the treatment of different diseases and recently there is inclination to use herbal formulations are on increasing demand. This increase in
Submission Date: 28-04-2020; Revision Date: 22-06-2020; Accepted Date: 07-09-2020

DOI: 10.5530/ijper.54.3s.168 Correspondence: Dr. Sunil Jalalpure Professor, KLE College of Pharmacy Belagavi and Dr. Prabhakar Kore Basic Science Research Center, KLE Academy of Higher Education and Research, Nehru Nagar, Belagavi-590010 Karnataka, INDIA.

Phone: +919448964057

E-mail: jalalpuresunil@ rediffmail.com

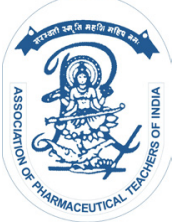

www.ijper.org 
demand for herbal medicines or ayurvedic formulations unavoidably led to the issue of obtaining and maintaining their quality. Hence forth, there has been increased care for the quality control of herbal related or ayurvedic formulations. In the current investigation, an attempt has been performed for the analysis of Ayurvedic marketed formulations with special reference to quantitative estimation of piperine in Trikatu Churna, Ajamodadi Churna and Chitrakadi Gutika.

To date, very few analytical methods are available for the quantification of piperinein theseAyurvedic formulations; however these do not provide an easy estimation. Many more analytical techniques have been reported for the estimation of piperine in black pepper, herbal formulation, plasma samples and nanoformulations. ${ }^{4-11}$ However, the reported HPLC techniques have several drawbacks like high flow rates, ${ }^{6,9}$ expensive, ${ }^{8,9}$ less sensitive, ${ }^{10}$ multiple wavelengths, ${ }^{9}$ lack of stability studies. ${ }^{7,8,11}$ Hence, the current investigation was aimed with to establish HPLC method for the accurate Piperine estimation from Ayurvedic marketed formulations.

Owing to intense first-pass metabolism, $\mathrm{pH}$-mediated metabolism of piperine to piperidine and sensitive nature of it during formulation and storage leads to photoisomerization, leads to difficulty in the administration of piperine and reduced its activity. ${ }^{12,13}$ Hence, to overcome these limitations an approach with lipid based nanoformulation has been investigated. In this regard the present investigation also highlights on the formulation of piperine loaded cubosome followed by the application of the established method for piperine quantification in the formulated nanoparticles. The present research was aimed with to establish a simple, rapid and stability showing RP-HPLC method to estimate piperine in nanoparticles, black pepper and Ayurvedic marketed formulations. Subsequently, stress degradation study under different forced or stress conditions were investigated to validate the established RP-HPLC method in the selection of experimental conditions and formulation design and analysis.

\section{MATERIALS AND METHODS}

\section{Materials}

Piperine (95\%) and Glyceryl monooleate (GMO) were received as free samples from Ms. Sami Labs Ltd., Bangaluru, India and Mohini Organics Pvt. Ltd. Mumbai, India, respectively. Black pepper, Trikatu churna, Ajmodadi churna and Chitrakadi gutika were procured from the Local Ayurvedic Pharmacy, Belagavi, India. Pluronic F-127 (PF-127) was purchased from Sigma Aldrich, USA. HPLC-grade acetonitrile
$(\mathrm{ACN})$, methanol and orthophosphoric acid (OPA) were procured from Merck, Mumbai, India and Fisher Scientific Mumbai, India. Deionized water obtained after filtration through Millipore Direct-Q ${ }^{\circledR}-3$ equipment (Molsheim, France) was used for the analysis.

\section{Instrument and experimental conditions}

HPLC system (LC-20AD prominence equipment, Shimadzu, Japan) consisting of SPD-M20A PDA detector, LC- 20AD pump, a SIL-20AC HT auto sampler and CBM-20A communication bus module, operated through Shimadzu LC solution software (version 1.25). Luna C18 $(150 \times 4.6 \mathrm{~mm}$ i.d., $5 \mu \mathrm{m})$ column provided with guard column $(4 \times 3.0 \mathrm{~mm}$ i.d.) of Phenomenex, USA and $30^{\circ} \mathrm{C}$ of column temperature were used for separation. The mobile phase consists of ACN: $0.01 \%$ OPA [60:40 v/v; $\mathrm{pH} 3]$ and pumped at a flow rate of $1 \mathrm{~mL} / \mathrm{min}$. The solvents were degassed and filtered through Millex HV® polyvinylidene fluoride membrane filters $(0.45 \mu \mathrm{m}$; Millipore, Bedford, USA). Sample injection volume was kept $10 \mu \mathrm{L}$ and detection of piperine was done at $340 \mathrm{~nm}$.

\section{Preparation of calibration standards}

A methanolic stock solution $(1 \mathrm{mg} / \mathrm{mL})$ of piperine was prepared and used for calibration standard preparations of piperine in the series of concentrations of 0.5 $20 \mu \mathrm{g} / \mathrm{mL}$, by diluting stock with mobile phase. All solutions were kept in light resistant volumetric flasks to prevent possible photoisomerization.

\section{Validation of developed method}

Validation of developed method was done by using system suitability, linearity and limit of detection (LOD), limit of quantification (LOQ), precision, accuracy and stability as per ICH guidelines. ${ }^{14}$

\section{Preparation of Cubosome nanoparticles}

Piperine entrapped cubosome nanoparticles were formulated by using top-down method. The fragmentation techniques were used to formulate cubosomes using high speed homogenization followed by probe sonication method. ${ }^{15}$ Briefly, Piperine (30 $\mathrm{mg}$ ) and a previously optimized (refer to an upcoming paper) Pluronic F-127 (PF-127, 0.3 gm) and Glyceryl monooleate $(\mathrm{GMO}, 1.5 \mathrm{gm})$ were liquefied in separate container on a magnetic stirrer at $65^{\circ} \mathrm{C}$. Piperine was added in melted GMO and was mixed with liquefied PF-127 solution. This mixture was then incorporated to water(preheated) with constantstirring. Homogenization (IKA T25, Germany) was performed for 15 min with $15,000 \mathrm{rpm}$ to form a fine dispersion and thereafter, probe sonicated ( 5 min; RivoTEK, Mumbai) to form 
cubosomal nanoformulation. After $24 \mathrm{hr}$ of equilibrium, cubosome was further characterized for particle size, PDI and zeta potential by DLS (Zetasizer Nano ZS, UK). Entrapment efficiency of cubosome was determined by centrifuging (Eppendorf laboratory centrifuge, 5424R, Germany) the formulation for 15 min with $1500 \mathrm{rpm}$. The supernatant obtained after centrifugation process was processed for analyzing entrapment efficiency using HPLC. For the determination of loading capacity, weighed accurately the cubosomes nanoparticles were dispersed in methanol and vortexed for $10 \mathrm{~min}$. The drug content was then analyzed using HPLC. The morphology of cubosome was observed by high resolution TEM (Jeol/JEM, 2100).

\section{Method applicability for estimation of piperine in Black pepper and ayurvedic marketed products}

Black pepper and ayurvedic marketed products containing piperine (Trikatu Churna, Ajamodadi Churna and Chitrakadi Gutika) were used for estimation of piperine content using developed HPLC method. Black pepper and Chitrakadigutika were powdered using mortar and pestle to obtain fine powder. The powdered black pepper and other ayurvedic marketed products weighed accurately and dissolved in methanol to obtain $1 \mathrm{mg} / \mathrm{ml}$ stock solution. The light resistant volumetric flasks holding above samples were sonicated for $10 \mathrm{~min}$ and filtered using a $0.45 \mu \mathrm{m}$ syringe filter. The sample was finally diluted with mobile phase and estimated for piperine content using HPLC.

\section{Stress degradation Assay}

It is generally advisable to control the degradation conditions to prevent it from maximum amount of degradation; hence $2 \mathrm{hr}$ is mostly preferred for the (mild-strong) stress degradation studies. In the present study, stress degradation assays were performed for $2 \mathrm{hr}$ as per ICH recommended stress conditions. For every stress degradation assay sample preparation were performed as a) Normal drug solution ( $0 \mathrm{~h}$ ) and b) drug solutions subjected for degradation for $2 \mathrm{hr}$. Acid-base degradation studies were performed by treating piperine drug solution $(1 \mathrm{~mL})$ with $1 \mathrm{M} \mathrm{HCl}(1 \mathrm{~mL})$ and $1 \mathrm{M}$ $\mathrm{NaOH}(1 \mathrm{~mL})$ solutions, individually in a separate light resistant volumetric flask. Sealing of the flasks were done followed by heating $\left(80^{\circ} \mathrm{C}\right)$ for the duration of 2 h. Before HPLC evaluation, both the sample solutions were neutralized. In oxidative degradation study, drug solution $(1 \mathrm{~mL})$ was treated with hydrogen peroxide $\left(30 \% \mathrm{H}_{2} \mathrm{O}_{2} ; 1 \mathrm{~mL}\right)$, whereas in thermal degradation drug solution $(1 \mathrm{~mL})$ was treated with methanol (2 mL). Sealing of the flasks containing oxidative and thermal degradation samples were performed, followed by heating $\left(80^{\circ} \mathrm{C}\right)$ for the duration of $2 \mathrm{~h}$. In photodegradation study, drug solution $(1 \mathrm{~mL})$ was diluted with mobile phase in transparent volumetric flask up to $10 \mathrm{~mL}$, sealed and kept outside under the sunlight for $2 \mathrm{hr}$. For all above degradation studies, the sample solutions were appropriately diluted with mobile phase, filtered and processed for HPLC system. ${ }^{16-18}$

\section{Statistical analysis}

All the results of validation and stress degradation studies were carried out in triplicates or six times and data were expressed as mean \pm SD. Microsoft excel was used to calculate mean, standard deviation, \% relative standard deviation ( $\% \mathrm{RSD})$, slope and correlation coefficient of the experimental data. ANOVA analysis was performed for the calibration curve of piperine by GraphPad Prism software (GraphPad Software Inc., CA, USA).

\section{RESULTS AND DISCUSSION Method development}

In the current investigation, a stability indicating RP-HPLC method was successfully established for piperine estimation in cubosome, black pepper and Ayurvedic marketed formulations. The established HPLC method was also employed to evaluate the stress degradation behavior of piperine under various stress environments. The developed method was selected on the basis of different chromatographic parameters namely mobile phase composition, flow rate and column oven temperature to get sharp and intense peaks. The sharpness and peak intensity was decided on the basis of peak height, peak area, peak width and tailing if any present. In addition to that, they obtained peak is considered good if there is absence of peak broadening, shoulder peak and peak splitting. Firstly, the results obtained from the mobile phase consisting $\mathrm{ACN}$ : water have shown less intense peak with poor resolution. When ACN was replaced with the methanol, some additional peaks were obtained with considerable increased resolution; less sharpness and tailing were observed for piperine peak. Therefore, for further method development, ACN and buffer such as OPA $(0.1 \% \mathrm{v} / \mathrm{v})$ were considered in the mobile phase mixture. It was observed from the results the concentration of OPA has affected the peak characteristic and other parameters. OPA $(0.1 \% \mathrm{v} / \mathrm{v})$ had given the broad peak with poor resolution, hence to improve the peak characteristics; concentration of OPA was reduced to $0.01 \% \mathrm{v} / \mathrm{v}$. The mobile phase comprising ACN and 
0.01\% OPA (60:40 v/v; $\mathrm{pH} 3)$ provided sharp, intense and good resolved peak with $4.67 \mathrm{~min}$ of retention time (Figure 1A). The increased flow rate caused tailing, whereas reduced flow rate given broadness and longer retention time, hence flow rate with $1 \mathrm{~mL} /$ min was observed to be most suitable with all peak characteristics. Changes made in the oven temperature $\left(20-40^{\circ} \mathrm{C}\right)$ had also shown considerable effect on the peak characteristics and retention time. A sharp, intense peak with less retention time was achieved by optimized oven temperature of $30^{\circ} \mathrm{C}$.

\section{Method validation}

\section{System suitability}

Suitability of the HPLC system confirms the feasibility and acceptability of the developed HPLC method. The results of different system suitability parameters namely peak area, retention time (tR), tailing factor and plate count were observed to be in acceptable range (Table 1). The sharp and intense peak was obtained for piperine as shown in Figure 1A.

The data resulted from the parameters of system suitability study demonstrated the method was suitable to perform further analysis of piperine in different formulations.

\section{Linearity}

Linearity of the developed method is the linear relation between the peak areas and their correspondence concentrations. The regression analysis data demonstrated that the developed method was linear with the different series of concentrations (0.5-20 $\mu \mathrm{g} / \mathrm{mL}$ ) of piperine, which were estimated at $340 \mathrm{~nm}$ with correlation coefficient $R^{2}>0.999$ and suggesting acceptable linearity (Table 2; Figure 2). ANOVA analysis for piperine also proved that the regression model is statistically significant which predicts the outcome variable $(P<0.05)$ (Table 3).

\section{Limit of quantification (LOQ) and Limit of detection (LOD)}

LOD and LOQ are the analytes is the lowest detectable and quantifiable concentration which gives signal to noise ratio of $3: 1$ and 10:1 respectively. At $340 \mathrm{~nm}$, the detection and quantification limit were observed to be 0.015 and $0.044 \mu \mathrm{g} / \mathrm{mL}$ for piperine indicating the developed HPLC technique was sensitive to determine piperine concentration in cubosome nanoparticles and marketed products (Table 2).

\section{Precision}

The precision is the measure of closeness of agreement between the numbers of measurements obtained from numbers of samples of the same sample under the provided steps. ${ }^{19}$ Both inter-day (on three succeeding days) and intra-day (on the same day) analysis were performed at different concentrations (low, medium and high) and results are shown in Table 4. The values for percent RSD in intra-day precision and inter-day precision ranged between $1.20-1.78 \%$ and $0.92-1.84 \%$ respectively, which were $<2 \%$, indicating both precision assays satisfies acceptance criteria and demonstrated the precise characteristic of the developed method.

\section{Accuracy}

Accuracy of developed HPLC method was indicated by the closeness value or percent difference between experimental and true value. ${ }^{20}$ Known concentrations of piperine were spiked to their preanalyzed sample $(2$ $\mu \mathrm{g} / \mathrm{mL}$ ) at variable levels of concentrations (50, 100 and $150 \%$ ). The mean percent recoveries were in the range of 99.04 to $101.93 \%$ for piperine (Table 5), which indicates that the developed method was applicable for extensive scale of sample investigation.

\section{Robustness}

Robustness is the capability of the developed method to remain unaltered by slight intentional changes in chromatographic parameters. The robustness of the developed HPLC technique was analyzed on the basis parameters like percent RSD and retention time obtained, after introducing intentional variations in the mobile phase flow rate $( \pm 0.1 \mathrm{~mL} / \mathrm{min})$, OPA concentration $( \pm 0.09 \%)$, mobile phase ratio $( \pm 2 \%)$ and oven temperature $\left( \pm 5^{\circ} \mathrm{C}\right)$. It was demonstrated that the percent RSD $(<1)$ values and system suitability parameters were remain to be not affected (Table 6), confirming the developed HPLC method is robust.

\section{Cubosome characterization}

In the present study, blank and piperine-loaded cubosome were successfully formulated by homogenizer method. The particle size, PDI and zeta potential for blank cubosome were $101 \mathrm{~nm}, 0.14$ and $-12.1 \mathrm{mV}$ respectively, whereas for piperine-loaded cubosome those were 114 $\mathrm{nm}, 0.16$ and $-29.8 \mathrm{mV}$ respectively (Table 7). The low

\begin{tabular}{|c|c|c|c|}
\hline \multicolumn{2}{|c|}{ Table 1: System suitability test parameters. } \\
\hline \multirow{2}{*}{ Parameter } & \multicolumn{2}{|c|}{ Piperine } & \multirow{2}{*}{$\begin{array}{c}\text { Acceptance } \\
\text { criteria }\end{array}$} \\
\cline { 2 - 3 } & Mean & SD & - \\
\hline Retention time (tR, min) & 4.67 & 0.006 & - \\
\hline Peak area & 549279 & 976 & - \\
\hline Plate count & 6523 & 122 & $>2000$ \\
\hline Tailing Factor & 1.13 & 0.01 & $\leq 2$ \\
\hline Assymetry factor & 1.12 & 0.01 & $\leq 2$ \\
\hline
\end{tabular}




\begin{tabular}{|c|c|c|c|c|c|}
\hline \multicolumn{7}{|c|}{ Table 2: Linearity parameters data. } \\
\hline $\begin{array}{c}\text { Concentration } \\
\text { range } \\
(\mu \mathrm{g} / \mathrm{mL})\end{array}$ & Slope & Intercept & $\begin{array}{c}\text { Regression } \\
\text { coefficient }\left(\boldsymbol{R}^{2}\right)\end{array}$ & $\begin{array}{c}\text { Limit of } \\
\text { Detection } \\
(\mu \mathrm{g} / \mathrm{mL})\end{array}$ & $\begin{array}{c}\text { Limit of } \\
\text { Quantification } \\
(\mu \mathrm{g} / \mathrm{mL})\end{array}$ \\
\hline $0.5-20$ & 65943 & 25272 & 0.999 & 0.015 & 0.044 \\
\hline
\end{tabular}

\begin{tabular}{|c|c|c|c|c|c|c|}
\hline \multicolumn{7}{|c|}{ Table 3: Results of ANOVA analysis for calibration curve of Piperine } \\
\hline Model & SS & df & MS & F & $\boldsymbol{R}^{2}$ & $\boldsymbol{P}$ value \\
\hline $\begin{array}{c}\text { Treatment (between } \\
\text { columns) }\end{array}$ & 16221 & 2 & 8111 & & & \\
\cline { 1 - 4 } $\begin{array}{c}\text { Individual (between } \\
\text { rows) }\end{array}$ & $3.699 \mathrm{e}+012$ & 5 & $7.399 \mathrm{e}+011$ & $2.995 \mathrm{e}+007$ & 1.000 & $<0.0001$ \\
\hline Residual (random) & 247036 & 10 & 24704 & & & \\
\hline Total & $3.699 \mathrm{e}+012$ & 17 & & & \\
\hline
\end{tabular}

SS- Sum of squares; df- degree of freedom; MS- Mean square; F- Fischer statistics value; $\mathrm{R}^{2}$ - Regression coefficient; $P$ value- Probability value

PDI values represented homogeneous nature with uniformly dispersed particles in the cubosome. ${ }^{21}$ Zeta potential is an important factor in evaluating nanoparticle stability, ${ }^{22}$ which demonstrated from the results that the negative charge on the cubosome nanoparticles was exerted, may be due to GMO containing free fatty acids. It was observed from the obtained chromatogram of cubosome that there were absence of interfering peaks of excipients used in the cubosome formulation with the parent peak of piperine, which was sharp and intense (Figure 1B). In the analysis of percent EE of cubosome, the concentration of piperine entrapped in the cubosome was evaluated by the developed analytical method, which was observed to be $86.31 \%$. The percent drug loading capacity was found to be $1.15 \%$ (Table 6). The low drug loading value indicates that the piperine is preferably located in the aqueous phase rather than in lipid structures.

The morphology of the cubosome nanoparticles was investigated by the HR-TEM analysis. These cubosome particles appeared to be cubic, uniform, smooth surface with less curvature (Figure 3). The scattered particles are in the nano range and well separated from each other. The brightness around the cubic border structure indicates self-assembled lipid bilayer structure.

\section{Analysis in black pepper and Ayurvedic marketed products}

The established analytical method was considered in the determination of piperine content in black pepper and commercial available Ayurvedic marketed products.

The percent piperine content in Black pepper, Trikatu Churna, Ajamodadi Churna and Chitrakadi Gutika were found to be 98.16, 98.59, 99.20 and $98.83 \%$ respectively, which was within the range of acceptable

\begin{tabular}{|c|c|c|c|c|}
\hline Table 4: Intra-day and inter-day precision of piperine. \\
\hline $\begin{array}{c}\text { Piperine } \\
\text { concentration } \\
(\boldsymbol{\mu g} / \mathbf{m L})\end{array}$ & $\begin{array}{c}\text { Intra-day } \\
\text { RSD (\%) }\end{array}$ & \multicolumn{3}{|c|}{ Inter-day RSD (\%) } \\
\cline { 3 - 5 } & $\mathbf{1}^{\text {st }}$ Day & $\mathbf{2}^{\text {nd }}$ Day & $\mathbf{3}^{\text {rd }}$ Day \\
\hline 1 & 1.55 & 0.92 & 1.70 & 0.96 \\
\hline 2 & 1.20 & 1.49 & 1.55 & 1.73 \\
\hline 5 & 1.78 & 1.81 & 1.84 & 1.43 \\
\hline
\end{tabular}

(n=3); RSD-Relative Standard Deviation.

Table 5: Evaluation of accuracy based on percent Recovery of piperine.

\begin{tabular}{|c|c|c|}
\hline Level of added piperine (\%) & Recovery (\%) & RSD (\%) \\
\hline 50 & 99.04 & 1.71 \\
\hline 100 & 101.93 & 0.72 \\
\hline 150 & 100.47 & 1.57 \\
\hline
\end{tabular}

$(n=3)$; RSD-Relative Standard Deviation.

as per the labeled claim. The absence of interfering peaks observed for the HPLC chromatograms of black pepper and other marketed formulations indicated that other drugs and ingredients used in the marketed formulations did not interfere with the parent peak of piperine which demonstrated that this developed analytical method is applicable for routine evaluation of piperine in quality control laboratories (Figure 4).

\section{Stress degradation assays}

The data obtained from the stress degradation assays are presented in Table 8 . The method applicability was proved from the obtained HPLC chromatograms where adequate separation was seen between drug peak and their degrading peaks (Figure 5).

It was observed from the acid degradation that the percent degradation of piperine was $51.64 \%$, which 


\begin{tabular}{|c|c|c|c|c|c|c|c|}
\hline \multicolumn{7}{|c|}{ Table 6: Results of Robustness assay. } \\
\hline \multirow{2}{*}{ Parameters } & $\begin{array}{c}\text { Variation } \\
\text { made }\end{array}$ & tR \pm S.D. & $\begin{array}{c}\text { RSD } \\
(\%)\end{array}$ & T.F. \pm S.D. & $\begin{array}{c}\text { RSD } \\
(\%)\end{array}$ & $\begin{array}{c}\text { Plate count } \pm \\
\text { S.D. }\end{array}$ & $\begin{array}{c}\text { RSD } \\
(\%)\end{array}$ \\
\hline \multirow{2}{*}{$\begin{array}{c}\text { Composition of } \\
\text { Mobile phase } \\
\text { (ACN:0.01\% OPA) }\end{array}$} & $60: 40$ & $4.67 \pm 0.006$ & 0.12 & $1.13 \pm 0.01$ & 0.88 & $6523 \pm 122$ & 1.87 \\
\cline { 2 - 8 } & $58: 42$ & $4.65 \pm 0.006$ & 0.12 & $1.29 \pm 0.009$ & 0.69 & $6802 \pm 98$ & 1.44 \\
\hline \multirow{2}{*}{$\begin{array}{c}\text { Concentration of } \\
\text { OPA }\end{array}$} & $62: 38$ & $4.73 \pm 0.010$ & 0.21 & $1.35 \pm 0.008$ & 0.59 & $6020 \pm 102$ & 1.69 \\
\cline { 2 - 8 } & $0.10 \%$ & $4.69 \pm 0.010$ & 0.21 & $1.02 \pm 0.006$ & 0.58 & $6902 \pm 64$ & 0.92 \\
\hline \multirow{2}{*}{\begin{tabular}{c} 
Flow rate \\
\cline { 2 - 8 }
\end{tabular}} & $1 \mathrm{~mL} / \mathrm{min}$ & $4.67 \pm 0.006$ & 0.12 & $1.13 \pm 0.01$ & 0.88 & $6523 \pm 122$ & 1.87 \\
\cline { 2 - 8 } & $1.1 \mathrm{~mL} / \mathrm{min}$ & $4.89 \pm 0.010$ & 0.20 & $1.20 \pm 0.010$ & 0.83 & $7010 \pm 52$ & 0.74 \\
\hline \multirow{2}{*}{$\begin{array}{c}\text { Column oven } \\
\text { Temperature }\end{array}$} & $4.32 \pm 0.015$ & 0.35 & $0.98 \pm 0.009$ & 0.91 & $6008 \pm 60$ & 0.99 \\
\cline { 2 - 8 } & $35^{\circ} \mathrm{C}$ & $4.67 \pm 0.006$ & 0.12 & $1.13 \pm 0.01$ & 0.88 & $6523 \pm 122$ & 1.87 \\
\hline
\end{tabular}

tR- Retention time; T.F.- Tailing factor; S.D. - Standard deviation; RSD - Relative Standard Deviation.

\begin{tabular}{|c|c|c|c|c|c|}
\hline \multicolumn{7}{|c|}{ Table 7: Cubosome Nanoparticles Characterization. } \\
\hline $\begin{array}{c}\text { Cubosome } \\
\text { preparation }\end{array}$ & $\begin{array}{c}\text { Diameter } \\
(\mathbf{n m})\end{array}$ & $\begin{array}{c}\text { Polydispersibility } \\
\text { index }\end{array}$ & ZP (mV) & $\begin{array}{c}\text { Entrapment } \\
\text { Efficiency (\%) }\end{array}$ & $\begin{array}{c}\text { Drug } \\
\text { loading (\%) }\end{array}$ \\
\hline BC & $101 \pm 9.06$ & $0.14 \pm 0.02$ & $-12.1 \pm 2.69$ & -- & -- \\
\hline PC & $114 \pm 4.22$ & $0.16 \pm 0.10$ & $-29.8 \pm 1.20$ & $86.31 \pm 0.67$ & $1.15 \pm 0.11$ \\
\hline
\end{tabular}

$\mathrm{n}=3$; Mean \pm Standard Deviation (SD), ZP- Zeta potential, BC- Blank cubosome, PC- Piperine entrapped cubosome

shown two small insignificant degraded peaks in acid degradation environment. In alkaline degradation study, piperine was less prone to degrade at lower percentage $(37.11 \%)$ with one small degrading peak. It was observed from the acid and alkaline degradation studies that, piperine was more stable over the alkaline stress condition as compared to acid stress condition, as piperine more favorable in alkaline condition and suggesting good stability of the developed method. The HPLC chromatogram obtained under thermal degradation study suggesting heating at $80^{\circ} \mathrm{C}$ for 2 hr does not affected stability of piperine, as the peak appeared exactly similar to normal peaks, absence of degrading peaks and negligible percent degradation. This might be because of high melting temperature of piperine, which doesn't affect their stability. In oxidative degradation study, at the retention time 2.38 min a peroxide peak was seen with percent degradation for piperine was $32.65 \%$. In photodegradation study (sunlight $2 \mathrm{~h}$ ), piperine was almost $74.84 \%$ was degraded. It was observed from the HPLC chromatogram the parent peak was diminishing and the degrading peaks were more intensely appeared. Dilute piperine solution more prone to photodegradation which has given two distinguishable degradation peaks. This might be because of piperine converts to their degrading product piperidine.
Table 8: Results for stress degradation assay.

\begin{tabular}{|c|c|}
\hline Stress degradation study & \% Drug degradation \\
\hline Acidic $(1 \mathrm{M} \mathrm{HCl})$ & $51.64 \pm 1.24$ \\
\hline Basic $(1 \mathrm{M} \mathrm{NaOH})$ & $37.11 \pm 1.71$ \\
\hline Thermal & $2.05 \pm 1.08$ \\
\hline Oxidative & $32.65 \pm 1.65$ \\
\hline Photolytic (Sunlight) & $74.84 \pm 1.03$ \\
\hline
\end{tabular}

$n=3$; Mean \pm Standard Deviation (SD)
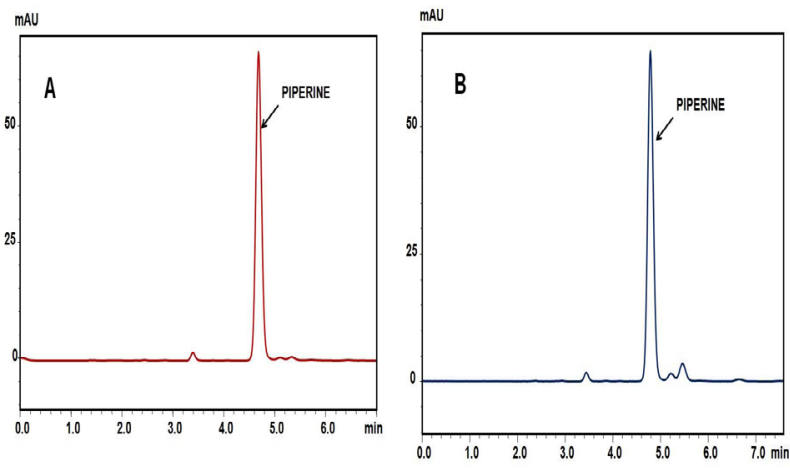

Figure 1: HPLC chromatograms for piperine $(A)$ and piperine entrapped in cubosome nanoparticles (B) at $\lambda_{\max } 340 \mathrm{~nm}$.

Under all stress degradation conditions, drugs peak integrity was maintained with nothing effect on the retention time. 
Table 9: Comparison between previously published HPLC methods.

\begin{tabular}{|c|c|c|c|c|c|c|}
\hline $\begin{array}{l}\text { Sr. } \\
\text { No. }\end{array}$ & $\begin{array}{l}\text { Mobile phase } \\
\text { And flow rate }\end{array}$ & $\begin{array}{l}\text { Wavelength } \\
\quad(\mathrm{nm})\end{array}$ & Column & Limitations & Application & Ref. \\
\hline \multicolumn{7}{|c|}{ Piperine } \\
\hline 1 & $\begin{array}{l}\text { Methanol and water }(50: 50) \\
\text { Flow rate: } 2 \mathrm{ml} / \mathrm{min}\end{array}$ & 280 and 345 & $\begin{array}{l}\text { A stainless- } \\
\text { steel } \mu \\
\text { Bondapak CN } \\
\text { column }\end{array}$ & $\begin{array}{l}\text { High flow } \\
\text { rate and less } \\
\text { sensitive }\end{array}$ & $\begin{array}{c}\text { Rapid analysis of piperine } \\
\text { in pepper and non-volatile } \\
\text { ether extracts. }\end{array}$ & 6 \\
\hline 2 & $\begin{array}{c}25 \mathrm{mM} \mathrm{KH}_{2} \mathrm{PO}_{4}(\mathrm{pH} 4.5)- \\
\text { acetonitrile }(35: 65) \\
\text { Flow rate: } 1 \mathrm{ml} / \mathrm{min}\end{array}$ & 340 & $\mathrm{C}_{18}$ & $\begin{array}{l}\text { Lack of stability } \\
\text { study analysis in } \\
\text { plasma }\end{array}$ & $\begin{array}{l}\text { Analysis of piperine } \\
\text { in rat plasma and } \\
\text { methods applicability in } \\
\text { pharmacokinetic study }\end{array}$ & 7 \\
\hline \multicolumn{7}{|c|}{ Piperine and other drugs } \\
\hline 5 & $\begin{array}{c}0.1 \% \text { ortho phosphoric } \\
\text { acid aqueous solution and } \\
\text { acetonitrile } \\
(45: 55, \mathrm{v} / \mathrm{v}) \\
\text { Flow rate: } 1.2 \mathrm{ml} / \mathrm{min}\end{array}$ & 262 & $\mathrm{C}_{18}$ & $\begin{array}{l}\text { Absence of } \\
\text { stability study, } \\
\text { expensive }\end{array}$ & $\begin{array}{l}\text { Simultaneous } \\
\text { estimation of curcumin and } \\
\text { piperine with adequate } \\
\text { separation and applied for } \\
\text { estimation in nanoparticles }\end{array}$ & 8 \\
\hline 6 & $\begin{array}{c}\text { Acetonitrile : methanol : } \\
\text { trifluoroacetic } \\
\text { Acid : water }(17.6: 35.3: 0.1 \\
: 47.0, \mathrm{v} / \mathrm{v} / \mathrm{v} / \mathrm{v}) \\
\text { Flow rate }: 1.2 \mathrm{ml} / \mathrm{min}\end{array}$ & $\begin{array}{l}\text { curcumin-415nm, } \\
\text { piperine-335nm , } \\
\text { b-17-estradiol } \\
\text { acetate-280nm } \\
\text { (internal standard) }\end{array}$ & $\begin{array}{l}\text { Chromolith1 } \\
\text { Speed ROD } \\
\text { RP-18 }\end{array}$ & $\begin{array}{l}\text { Multiple } \\
\text { wavelength used } \\
\text { for detection, } \\
\text { expensive due to } \\
\text { high flow rate }\end{array}$ & $\begin{array}{c}\text { Simultaneous } \\
\text { estimation of } \\
\text { Piperine and Curcumin in } \\
\text { Plasma (human) } \\
\text { and also applied for Clinical } \\
\text { Pharmacological evaluation }\end{array}$ & 9 \\
\hline 7 & $\begin{array}{l}\text { Acetonitrile:Water }(60: 40 \text {, } \\
\qquad \mathrm{v} / \mathrm{v}) \\
\text { Flow rate }: 1 \mathrm{ml} / \mathrm{min}\end{array}$ & 240 & $\mathrm{C}_{18}$ & $\begin{array}{l}\text { Less sensitive } \\
\text { method to } \\
\text { detect lower } \\
\text { concentration }\end{array}$ & $\begin{array}{l}\text { Simultaneous estimation of } \\
\text { piperine and guggulsterones } \\
\text { in Unani dosage as well as in } \\
\text { a nanoemulsion }\end{array}$ & 10 \\
\hline 8 & $\begin{array}{c}25 \mathrm{mM} \text { Potassium dihydrogen } \\
\text { phosphate }(\mathrm{pH} 4.5) \text { : } \\
\text { Acetonitrile }(50: 50, \mathrm{v} / \mathrm{v}) \text { Flow } \\
\text { rate: } 1 \mathrm{ml} / \mathrm{min}\end{array}$ & 340 and 231 & $\mathrm{C}_{18}$ & $\begin{array}{c}\text { Absence of } \\
\text { stability study }\end{array}$ & $\begin{array}{l}\text { Simultaneous } \\
\text { estimation of piperine and } \\
\text { ketoconazole in rat plasma } \\
\text { and culture of hepatocyte }\end{array}$ & 11 \\
\hline
\end{tabular}

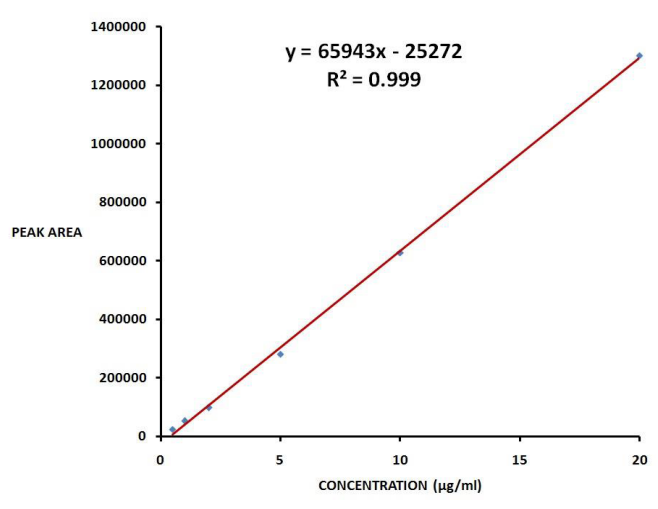

Figure 2: Linearity curve for Piperine.

\section{Comparison with previously published HPLC methods}

Comparative evaluation of previously published methods and the current developed HPLC method was performed on the basis of mobile phase ratios, mobile phase flow rate, wavelength, column, stability study, limitations and applicability of the HPLC methods. The

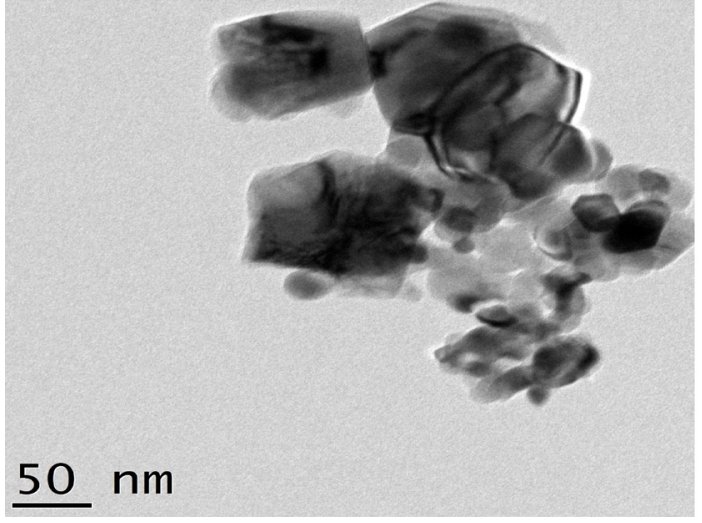

Figure 3: High resolution-transmission electronic microscopy (HR-TEM) of cubosome nanoparticles.

comparison data were represented in the Table 9. To date, there is no single HPLC method available which can be used for multiple analyses like estimation of piperine in nanoformulation, black pepper and marketed products and also to evaluate the degradation behavior of piperine using same parameters of developed HPLC method. The present method containing the mobile 

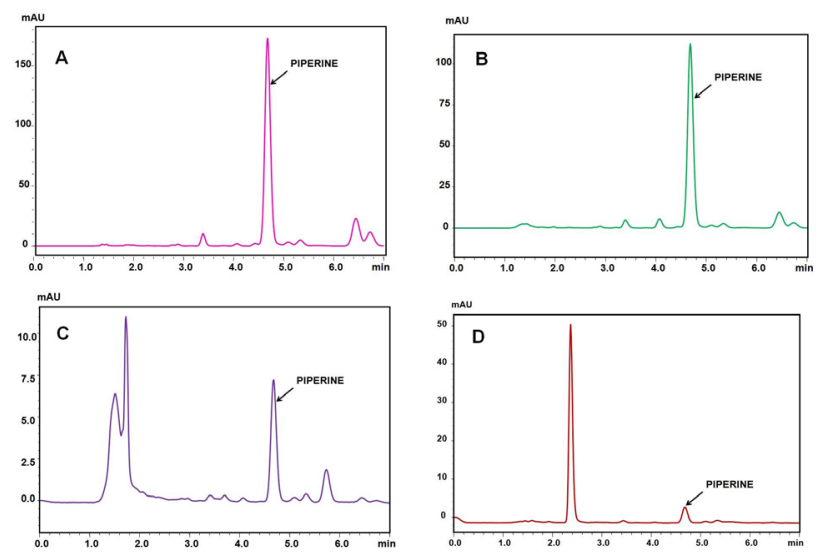

Figure 4: HPLC chromatograms for piperine obtained in the Black pepper (A), TrikatuChurna (B), AjamodadiChurna (C) and ChitrakadiGutika (D).
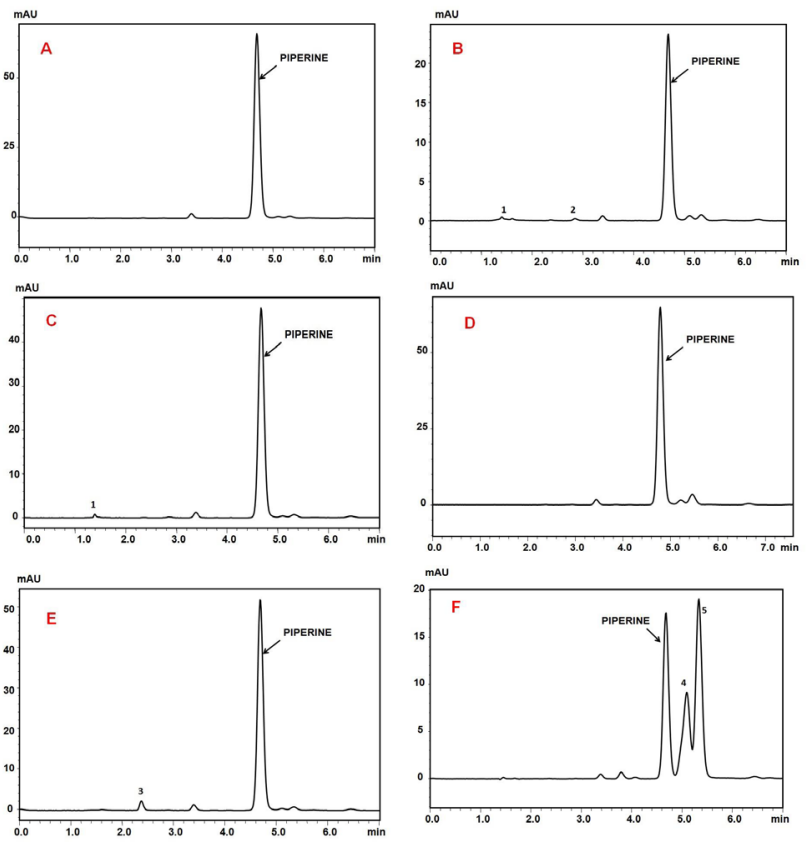

Figure 5: HPLC chromatograms of piperine $(10 \mu \mathrm{g} / \mathrm{mL})$ obtained in the stress degradation assays using $\operatorname{Normal}(A)$, Acidic (B), Basic (C), Thermal (D), Oxidation (E) and sunlight (F) stress conditions.

phase composition of ACN: 0.01\% OPA (60:40 v/v; $\mathrm{pH} 3), 1 \mathrm{~mL} / \mathrm{min}$ of flow rate with $340 \mathrm{~nm}$ as detection wavelength is found to be more sensitive, economic and stable when compared to other published literature.

\section{CONCLUSION}

A simple, specific, sensitive and stability indicating RPHPLC method was successfully developed and evaluated for piperine estimation in cubosome nanoformulation, black pepper and ayurvedic marketed products. This developed RP-HPLC method allows easy quantification of piperine as compared to previously developed methods. The validation of established method was done as per ICH guidelines, which were within the acceptable limits. The established method demonstrates accurate and easy estimation of piperine in cubosome, black pepper and ayurvedic marketed products indicating reliable and sensitive nature of method. The results of stress degradation study suggested that piperine was considerably stable against acidic, alkaline and high thermal conditions. However, piperine was susceptible to degradation against oxidative and photolytic stress conditions. Hence, this simple, stability indicating RP-HPLC method is helpful for further routine quality control analysis. This method could thus be used for regular in vitro and in vivo estimation of piperine.

\section{ACKNOWLEDGEMENT}

We are thankful to KAHER, Belagavi for financial support to carry out the research work. We acknowledge Sami Labs Ltd., Bengaluru and Mohini Organics, Mumbai for supplying the gift samples.

\section{CONFLICT OF INTEREST}

The authors hereby declare that they don't have conflict of interest.

\section{ABBREVIATIONS}

ACN: Acetonitrile; ICH: International Conference on Harmonization; RP-HPLC: Reverse-Phase High Performance Liquid Chromatography; i.d.: internal diameter; LOD: Limit of detection; LOQ: Limit of Quantification; GMO: Glyceryl monooleate; PF-127: Pluronic F-127; OPA: Orthophosphoric acid; DLS: Dynamic light scattering LC: Liquid Chromatography; RSD: Relative standard deviation; UV: Ultraviolet; PDA: Prominence Diode Array; RSD: Relative Standard Deviation; PDI: Polydispersibility index; EE: Entrapment Efficiency; HCl: Hydrochloric acid; $\mathrm{NaOH}$ : Sodium hydroxide.

\section{REFERENCES}

1. Sunila ES, Kuttan G. Immunomodulatory and antitumor activity of Piper longum Linn. and piperine. J Ethnopharmacol. 2004;90(2-3):339-46. https:// doi.10.1016/j.jep.2003.10.016.

2. Bhardwaj RK, Glaeser H, Becquemont L, Klotz U, Gupta SK, Fromm MF. Piperine, a major constituent of black pepper, inhibits human P-glycoprotein and CYP3A4. J Pharmacol Exp Ther, ASPET. 2002;302(2):645-50. https:// doi.org/10.1124/jpet.102.034728

3. Kurangi BK, Jalalpure SS. Review of selected herbal phytoconstituents for potential melanoma treatment. Indian J Heal Sci Biomed Res. 2018;11(1):3. https://doi.org/10.4103/kleuhsj.kleuhsj_319_17. 
4. Jasoliya J, Jani A. Method development and validation of RP-HPLC method for simultaneous estimation of resveratrol and piperine in combined capsule dosage form. World J Pharm Pharm Sci. 2014;3(5):1096-107.

5. Kurangi B, Jalalpure S, Jagwani S. A validated stability-indicating HPLC method for simultaneous estimation of resveratrol and piperine in cubosome and human plasma. J Chromatogr B Anal Technol Biomed Life Sci. 2019;11223. https://doi.org/10.1016/j.jchromb.2019.05.017

6. Rathnawathie M, Buckle KA. Determination of piperine in pepper (Piper nigrum) using high-performance liquid chromatography. J Chromatogr, 1983; 264:3(1) 320.

7. Bajada S, Singlab AK, Bedia KL. Liquid chromatographic method for determination of piperine in rat plasma: Application to pharmacokinetics. J Chromatogr B. 2002;776:245-49.

8. Moorthi C, Kumar CS, Mohan S, Krishnan K, Kathiresan K. Application of validated RP-HPLC-PDA method for the simultaneous estimation of curcumin and piperine in Eudragit E 100 nanoparticles. J Pharm Res. 2013;7(3):224-9. http://dx.doi.org/10.1016/j.jopr.2013.03.006.

9. Sethi P, Dua VK, Mohanty S, Mishra K, Jain R, Edwards G, et al. Journal of Liquid Chromatography and Related Technologies Development and Validation of a Reversed Phase HPLC Method for Simultaneous Determination of Curcumin and Piperine in Human Plasma for Application in Clinical Pharmacological Studies. J Liq Chromatogr. Relat Technol. 2009;32(20):2961-74. https://doi.org/10.1080/10826070903320178.

10. Kamal YT, Musthaba SM, Singh M, Parveen R, Ahmad S, Baboota S, et al. Development and validation of HPLC method for simultaneous estimation of piperine and guggulsterones in compound Unani formulation (tablets) and a nanoreservoir system. Biomed Chromatogr. 2011. https://doi.org/10.1002/ bmc.2676.

11. Bajad S, Johri RK, Singh K, Singh J, Bedi KL. Simple high-performance liquid chromatography method for the simultaneous determination of ketoconazole and piperine in rat plasma and hepatocyte culture. J Chromatogr A. 2002;949(1-2):43-7.

12. Bhat BG, Chandrasekhara N. Studies on the metabolism of piperine: Absorption, tissue distribution and excretion of urinary conjugates in rats. Toxicology. 1986;40(1):83-92.

13. Hashimoto K, Yaoi T, Koshiba H, Yoshida T, Maoka T, Fujiwara Y, et al. Photochemical isomerization of piperine, a pungent constituent in pepper. Food Sci Technol Int. 1996; 2(1): 24-29.
14. Validation of analytical procedure: Methodology International Conference on Harmonization. "ICH Harmonised tripartite guideline - Validation of analytical procedures: Text and methodology Q2(R1). 2005.

15. Ahirrao M, Shrotriya S. In vitro and in vivo evaluation of cubosomal in situ nasal gel containing resveratrol for brain targeting. Drug Dev Ind Pharm. 2017;43(10):1686-93. http://dx.doi.org/10.1080/03639045.2017.1338721

16. Kumar S, Lather V, Pandita D. Stability indicating simplified HPLC method for simultaneous analysis of resveratrol and quercetin in nanoparticles and human plasma. Food Chem. 2016;197:959-64. http://dx.doi.org/10.1016/j. foodchem.2015.11.078

17. Pangeni R, Sharma S. Design expert-supported development and validation of stability indicating high-performance liquid chromatography (HPLC) method for determination of resveratrol in bulk drug and pharmaceutical formulation. Int J Pharm Sci Res. 2015;6:5115-25. https://doi.org/10.13040/ IJPSR.0975-8232.6(12).5115-25.

18. Peram MR, Jalalpure S, Joshi SA, Palkar MB. A Single Robust RP-HPLC Analytical Method for Quantification of Curcuminoids in Commercial Turmeric Products, Ayurvedic Medicines and Nanovesicular Systems. J Liq Chromatogr Relat Technol. 2017; 40(10):487-98. https://doi.org/10.1080/10 826076.2017.1329742.

19. Jagwani S, Jalalpure S, Dhamecha D, Hua GS, Jadhav K. Development and Validation of Reverse-Phase High-Performance Liquid Chromatographic Method for Determination of Resveratrol in Human and Rat Plasma for Preclinical and Clinical Studies. Indian $\mathrm{J}$ of Pharmaceutical Education and Research. 2020;54(1):187-93. https://doi.org/10.5530/ijper.54.1.22

20. Jagwani S, Jalalpure S. A Stability Indicating Reversed Phase HPLC Method for Estimation of trans -Resveratrol in Oral Capsules and Nanoliposomes. TACL. 2019;9(5):711-26.

21. Dhamecha D, Jalalpure S, Jadhav K. Doxorubicin functionalized gold nanoparticles: Characterization and activity against human cancer cell lines. Process Biochem. 2015;50(12): 2298-306.

22. Jadhav K, Deore S, Dhamecha D, Rajeshwari H R, Jagwani S, Jalalpure S, et al. Phytosynthesis of Silver Nanoparticles: Characterization, Biocompatibility Studies and Anticancer Activity. ACS Biomater-Sci Eng. 2018;4(3):892-9. https://doi.org/10.1021/acsbiomaterials.7b00707

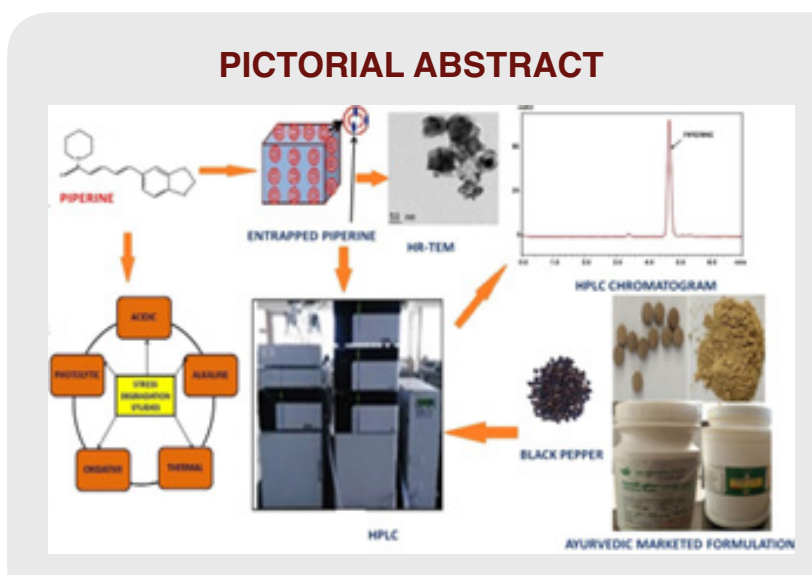

\section{SUMMARY}

RP-HPLC method was successfully developed and validated for piperine and successfully evaluated for its quantitative estimation in cubosome nanoparticles, black pepper and ayurvedic marketed products. The stability of the developed HPLC method was indicated by the stress degradation studies. The HPLC analysis was done by using Phenomenex $\mathrm{C}_{18}$ column using optimized mobile phase comprised of ACN: OPA $(60: 40, v / v), 1 \mathrm{~mL} / \mathrm{min}$ of flow rate with $340 \mathrm{~nm}$ as detection wavelength. The developed method was sensitive, accurate, precise and economical to detect piperine in cubosome nanoformulation and commercial marketed products. 


\section{About Authors}

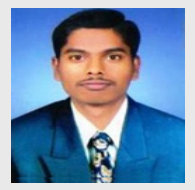

Mr. Bhaskar Kurangi, is a Ph.D scholar at KLE College of Pharmacy, Belagavi, and working at Dr. Prabhakar Kore Basic Science Research Center, KLE Academy of Higher Education and Research, Belagavi. His current research interest are development and evaluation of novel drug delivery systems, Analytical method development, Nanoparticulate drug delivery and its application to target cancers

Dr. Sunil Jalalpure is presently working as a Principal at KLE College of Pharmacy, Belagavi, K.L.E Academy of Higher Education and Research, Belagavi. His areas of research interests include isolation/ characterization of active principles from medicinal plants and their pharmacological screening for various biological activities and training the research students in Pharmacognosy, Phytochemistry and Biotechnological aspects with modern tools and techniques. He is recently involved in nanoparticle drug delivery system of herbal actives and green nanotechnology.

Cite this article: Kurangi B, Jalalpure S. A Validated Stability-indicating RP-HPLC Method for Piperine Estimation in Black Pepper, Marketed Formulation and Nanoparticles. Indian J of Pharmaceutical Education and Research. 2020;54(3s):s677-s686. 